\title{
Craniospinal Irradiation (CSI) in Acute Lymphoblastic Leukemia: Comparison between Conformal Radiotherapy, Intensity-Modulated Radiotherapy, and Helical Tomotherapy (HT)
}

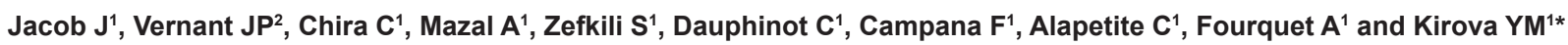

${ }^{1}$ Department of Radiation Oncology, Institut Curie, Paris, France

${ }^{2}$ Department of Hematology, Pitie Salpetriere Hospital, Paris, France

\begin{abstract}
Purpose: According to preliminary clinical experience, craniospinal irradiation (CSI) may be considered as a treatment option in patients with recurrent leukemia involving the central nervous system (CNS). Field matching poses challenges as it leads to a risk of underdosage or overdosage in the junctional area. We investigated the feasibility of CSI using helical tomotherapy (HT).
\end{abstract}

Patients and methods: Four patients presenting with CNS recurrences of leukemia were referred to our department for salvage radiation therapy. Treatment planning was conducted by the Eclipse ${ }^{\mathrm{TM}}$ system for 3D-CRT and IMRT, and with the Tomotherapy ${ }^{\circledR}$ software for HT. Acute adverse events were monitored weekly using the Common Terminology Criteria for Adverse Events v 4.0.

Results: Using HT, highly conformal irradiation could be delivered to CNS. Average doses to the encephalon were 25.1 Gy, $15.5 \mathrm{~Gy}$, and 23.3 Gy using 3D-CRT, IMRT, and HT respectively. Spinal cord received an average dose of 18.9 Gy with 3D-CRT, 15.7 Gy with IMRT and 23.4 Gy with HT. Areas of overdosage to the brain or the spinal cord were also significantly decreased with HT. With HT, average doses to critical organs were also significantly decreased. No acute toxicity was reported with HT, whereas the patients treated by 3D-CRT and IMRT presented with grade II vomiting and asthenia.

Conclusion: HT may optimize CSI in the treatment of CNS hematological recurrences by homogenously covering target volumes and improve clinical acute tolerance by more effectively sparing critical organs for preserving the quality of life. Further prospective assessments are warranted.

KeyWords: Craniospinal irradiation; Acute lymphoblastic leukemia; Central nervous system; Helical Tomotherapy

\section{Introduction}

Acute lymphoblastic leukemia (ALL) is a malignant hemopathy arising from clonal expansion of lymphoid blasts [1]. This heterogeneous disease is one of the most frequent malignancies in children in the United States [2]. In France, incidence rate in children younger than 15 years old was 34.3 cases per million per year [3], but data concerning adults is scarce. The register of Basse-Normandie region reports an incidence of $2.7 \%$ in the 1997-2004 period [4]. Several prognosis factors have been described [5,6] ALL rarely involve the central nervous system (CNS) at diagnosis [7], but the risk of relapse there without prophylaxis is particularly high $[8,9]$. Local neurologic recurrence alters prognosis $[10,11]$ and constitutes a therapeutic challenge.

Radiotherapy has been one of the therapeutic modalities for CNS prophylaxis and relapses in ALL for decades, although its potential for long-term toxicity prevents its choice as first line treatment at some centres, in favor of systemic and/or intrathecal treatments [12]. However, several techniques have emerged with efficient dose delivery and assurance of local control, while sparing healthy organs: first 3D-conformal radiotherapy (3D-CRT), then intensity-modulated radiotherapy (IMRT), and finally helical tomotherapy (HT) [13-15].

Here, we report our observations of four patients treated with craniospinal irradiation (CSI) via these three modalities at our institution for CNS-extended ALL. We also describe dosimetric studies for each method and clinical implications in terms of local control and acute tolerance.

\section{Patients and Methods}

\section{Case No.1}

A thirty-two-year-old woman was diagnosed with ALL in December 2007 characterized by the presence of the CALM/AF10 transcript $[10,11]$ (p13,q14) and normal karyotype. She was first treated with chemotherapy (Table 1) followed by an autologous bone marrow transplantation, leading to a complete remission. Due to her altered general status, the patient was administered fewer intrathecal injections for CNS prophylaxis (methotrexate, cytarabine, depomedrol) (Table 2) and no total body irradiation (TBI) during the conditioning of the autograft.

In August 2009, headaches revealed a meningeal relapse observed in the cerebrospinal fluid (CSF). Clinical examination and a complete evaluation of the bone marrow revealed normal results. Thus the patient was treated with intrathecal chemotherapy and corticosteroids. Due to

*Corresponding author: Dr. Youlia M. Kirova, Radiation Oncology, Institut Curie 26, Rue d'Ulm, 75005 Paris, France, Tel: 331443241 93; Fax: 33144324616 E-mail: youlia.kirova@curie.net

Received May 21, 2012; Accepted June 12, 2012; Published June 16, 2012

Citation: Jacob J, Vernant JP, Chira C, Mazal A, Zefkili S, et al. (2012) Craniospinal Irradiation (CSI) in Acute Lymphoblastic Leukemia: Comparison between Conformal Radiotherapy, Intensity-Modulated Radiotherapy, and Helical Tomotherapy (HT). J Nucl Med Radiat Ther S6:003. doi:10.4172/2155-9619.S6003

Copyright: ( 2012 Jacob J, et al. This is an open-access article distributed unde the terms of the Creative Commons Attribution License, which permits unrestricted use, distribution, and reproduction in any medium, provided the original author and source are credited. 
Citation: Jacob J, Vernant JP, Chira C, Mazal A, Zefkili S, et al. (2012) Craniospinal Irradiation (CSI) in Acute Lymphoblastic Leukemia: Comparison between Conformal Radiotherapy, Intensity-Modulated Radiotherapy, and Helical Tomotherapy (HT). J Nucl Med Radiat Ther S6:003. doi:10.4172/2155-9619.S6-003

Page 2 of 6

the persistence of the symptoms, a magnetic resonance imaging (MRI) was performed and showed a lesion of the cerebellum compatible with a chloroma. A tonsillar and transtentorial involvement was also observed.

A second round of chemotherapy including methotrexate and cytarabine was delivered. However, the first cycle was complicated by mental adverse events and severe respiratory failure, requiring an orotracheal intubation and ventricular derivation.

After clinical improvement, the patient received an intrathecal injection of liposomal cytarabine and corticosteroids, then a second cycle of systemic methotrexate and cytarabine. This treatment was successful from a biological and radiological point-of-view, manifested by CSF depletetion of blastic cells, marked shrinkage of the cerebellar lesion, and regression of the mass effect on MRI.

In order to reinforce this favorable tableau, CSI via 3D-CRT was deemed appropriate. The delivered dose was $18 \mathrm{~Gy}$ (1.8 Gy per fraction) to the CNS with a boost of $40 \mathrm{~Gy}$ to the cerebral posterior fossa, with $6 \mathrm{MV}$ and $20 \mathrm{MV}$ photons in the prone position.

\section{Case No.2}

A 14-year-old boy was diagnosed with Philadelphia-negative ALL with two myeloid markers (CD 13, CD 33) and hyperleukocytosis in March 2001. A chemotherapy induction (daunorubicin, vincristine, L-asparaginase, methylprednisolone) was performed and followed by a consolidation with cytarabine and cyclophosphamide. CNS prophylaxis was administered through intrathecal injections of methotrexate, cytarabine, and depomedrol.

Molecular residual disease was intact in August 2001 and was treated by intensive chemotherapy (Table 1) and prophylactic intrathecal injections (Table 2). Due to the absence of a geno-identic donor of bone marrow, a graft could not be performed.

In October 2009, at the age of 23 , the patient presented with headaches, revealing a CNS relapse. Blastic cells were found in the CSF, whereas Computed Tomography (CT) and MRI remained normal. Therefore, systemic treatment with methotrexate, cytarabine, and intrathecal injections (methotrexate, cytarabine, depomedrol) were administered.

\begin{tabular}{|c|c|c|c|c|c|}
\hline Patient & Age (years), gender & Diagnosis & Date of diagnosis & Systemic treatment & Graft \\
\hline 1 & 32 , female & ALL with CALM/AF10 transcript & December 2007 & $\begin{array}{l}\text { vincristine, daunorubicin, } \\
\text { methotrexate, cyclophosphamide, } \\
\text { prednisone }\end{array}$ & Yes (autograft) \\
\hline 2 & 14 , male & Acute biphenotypic leukaemia & March 2001 & $\begin{array}{l}\text { daunorubicin, vincristine, L-asparaginase, } \\
\text { methylprednisolone, cytarabine, cyclophosphamide } \\
\text { vincristine, } \quad \text { methotrexate, cytarabine, } \\
\text { L-asparaginase, cyclophosphamide, vindesine, } \\
\begin{array}{l}\text { daunorubicin, mercaptopurine (molecular residual } \\
\text { disease) }\end{array}\end{array}$ & No \\
\hline 3 & 45 , male & ALL Philadelphie + & December 2005 & $\begin{array}{l}\text { vincristine, dexamethasone, imatinib, methotrexate, } \\
\text { cytarabine } \\
\text { vincristine, methotrexate, L-asparaginase, dasatinib, } \\
\text { nilotinib, donor lymphocyte infusion (molecular } \\
\text { residual disease) }\end{array}$ & Yes (allograft) \\
\hline 4 & 58 , female & ALL following chronic myeloid leukaemia & March 2010 & $\begin{array}{l}\text { hydroxyurea, imatinib, idarubicin, } \\
\text { cytarabine, }\end{array}$ & No \\
\hline
\end{tabular}

ALL: Acute lymphoblastic leukemia.

Table 1: Patients' clinical and systemic treatment features.

\begin{tabular}{|c|c|c|c|c|c|c|}
\hline Patient & $\begin{array}{l}\text { CNS prophylactic } \\
\text { treatment }\end{array}$ & $\begin{array}{c}\text { Time to CNS } \\
\text { relapse (months) }\end{array}$ & CNS curative treatment & Graft & $\begin{array}{l}\text { Radiation therapy } \\
\text { modality }\end{array}$ & Delivered dose to CNS \\
\hline 1 & $\begin{array}{l}\text { IT methotrexate, } \\
\text { cytarabine, depomedrol }\end{array}$ & 20 & $\begin{array}{c}\text { IV methotrexate, cytarabine } \\
\text { IT liposomal cytarabine and } \\
\text { corticosteroids } \\
\text { CSI }\end{array}$ & No & $\begin{array}{c}\text { 3D-CRT } \\
6 \mathrm{MV} \text { photons }\end{array}$ & $\begin{array}{l}18 \text { Gy (10 fractions) + boost until } 40 \\
\text { Gy to cerebral posterior fossa }\end{array}$ \\
\hline 2 & $\begin{array}{l}\text { IT methotrexate, } \\
\text { cytarabine, depomedrol }\end{array}$ & 103 & $\begin{array}{c}\text { IV methotrexate, cytarabine } \\
\text { IT methotrexate, cytarabine, } \\
\text { depomedrol } \\
\text { CSI }\end{array}$ & Yes & $\begin{array}{c}\text { IMRT } \\
6 \text { and } 20 \mathrm{MV} \text { photons }\end{array}$ & $15 \mathrm{~Gy}$ (10 fractions) \\
\hline 3 & $\begin{array}{l}\text { IT methotrexate, } \\
\text { cytarabine, } \\
\text { corticosteroids }\end{array}$ & 56 & $\begin{array}{c}\text { IV cyclophosphamide, methotrexate, } \\
\text { doxorubicin, vincristine, cytarabine } \\
\text { and dexamethasone } \\
\text { IT liposomal cytarabine } \\
\text { CSI }\end{array}$ & No & $\begin{array}{c}\mathrm{HT} \\
6 \mathrm{MV} \text { photons }\end{array}$ & 23.4 Gy (13 fractions) \\
\hline 4 & No & 0 & $\begin{array}{l}\text { IV hydroxyurea, idarubicin, } \\
\text { cytarabine, } \\
\text { Oral imatinib, } \\
\text { IT cytarabine (conventional then } \\
\text { liposomal), methotrexate and } \\
\text { corticosteroids } \\
\text { CSI }\end{array}$ & No & $\begin{array}{c}\mathrm{HT} \\
6 \mathrm{MV} \text { photons }\end{array}$ & 23.4 Gy (13 fractions) \\
\hline
\end{tabular}

CNS: central nervous system, IT: intrathecal, IV: intravenous, CSI: craniospinal irradiation, 3D-CRT: three dimensional conformal radiotherapy, IMRT: intensity-modulated radiation therapy, $\mathrm{HT}$ : helical tomotherapy.

Table 2: Central nervous system treatment features. 
Citation: Jacob J, Vernant JP, Chira C, Mazal A, Zefkili S, et al. (2012) Craniospinal Irradiation (CSI) in Acute Lymphoblastic Leukemia: Comparison between Conformal Radiotherapy, Intensity-Modulated Radiotherapy, and Helical Tomotherapy (HT). J Nucl Med Radiat Ther S6:003. doi:10.4172/2155-9619.S6-003

Page 3 of 6

The patient received CSI (15 Gy, 1.5 Gy per fraction) by IMRT in prone position with $6 \mathrm{MV}$ photons beams to the the whole brain and 20 MV photons on the superior and inferior central neuraxis.

\section{Case No.3}

A 45-year-old man was treated by HT for neurological and testicular relapse of Philadelphia-positive ALL.

The disease was diagnosed in December 2005 and was treated first by induction chemotherapy comprised of vincristine, dexamethasone, and imatinib. CNS prophylaxis was also performed through intrathecal injections of methotrexate and cytarabine. Once complete remission was attained, consolidation chemotherapy by systemic methotrexate and cytarabine was delivered. In April 2006, an allograft was carried out after conditioning by TBI (12 Gy in six fractions) and cyclophosphamide.

The patient presented with two relapses. The first one occurred in December 2007 in peripheral blood and bone marrow. Molecular residual disease was diagnosed. Chemotherapy was delivered according to the Capizzi protocol (Table 1) followed by a maintenance regimen including dasatinib, nilotinib, and donor lymphocyte infusion. Prophylactic intrathecal injections of methotrexate, cytarabine, and corticosteroids were delivered.

The second recurrence developed in the right testicle and CNS in August 2010. Intensive chemotherapy (cyclophosphamide, methotrexate, doxorubicin, vincristine, cytarabine, and dexamethasone) and intrathecal injections (liposomal cytarabine) were administered (Table 2). Due to this second relapse, we decided to irradiate the two involved sites.

The irradiation was performed through HT with $6 \mathrm{MV}$ photons, 23.4 Gy (1.8 Gy per fraction) to the CNS and 24 Gy to the testicles because this was the region of the first recurrence. The first part of the irradiation included both testicles and took place in December 2010. The treatment was followed by a complication in the form of a grade I erythema treated with topical corticosteroids.

The irradiation of the CNS was performed in dorsal decubitus and started in January 2011. A prophylactic treatment against potential adverse effects was administered (prevention of headaches, nauseas by corticosteroids).

\section{Case No.4}

A 58-year-old woman presented in March 2010 with lumbar pains whose intensity progressively increased. The results of initial clinical and radiological examinations appeared normal. Two weeks later, a lack of motility in the lower right leg occurred. No abnormality regarding sensitivity and sphincters was observed. The first hematologic evaluation showed hyperleukocytosis $(200,000$ white cells $/ \mathrm{mm}^{3}, 12,000$ basophiles, and 8,000 eosinophiles), anemia (hemoglobin: $9.0 \mathrm{~g} / \mathrm{dl}$ ), thrombocytosis (560,000 platelets/ $\mathrm{mm}^{3}$ ), and $11 \%$ of blastic cells. The myelogram showed hyperplasia of granulopoiesis with basophilia, 9\% myeloblasts, and relative hypoplasia of erythropoiesis. Karyotype in peripheral blood showed the existence of the Philadelphia chromosome. Moreover, the CSF contained $88 \%$ blastic cells. MRI showed infiltration extending from the third lumbar to the first two sacral vertebrae. And so, the diagnosis of myeloid chronic Philadelphia-positive leukemia with an ALL aspect and extension to the CNS was established. After a cytoreduction by hydroxyurea, chemotherapy induction with idarubicin and cytarabine, accompanied with oral imatinib, was initiated in April 2010 (Table 1).
The CNS was locally treated with intrathecal methotrexate, cytarabine (conventional first, then liposomal), and corticosteroids (Table 2). Consolidation chemotherapy was delivered (idarubicin, cytarabine) from August to October with a cytogenetic complete response to the treatment. Imatinib and intrathecal injections of liposomal cytarabine were continued.

A bone marrow transplant could not be performed due to the absence of a compatible donor either among family members or in the international databank, a feto-placental allograft was counterindicated due to the prevalence of anti-human-leukocyte antibodies in the blood. A collection of peripheral stem cells also failed.

Hence, after deliberations by a multidisciplinary team considering this controlled disease, it was decided to perform CSI. The treatment was conducted in the supine position by $\mathrm{HT}$, using 6-MV photons and targeting the entire CNS (23.4 Gy, 1.8 Gy per fraction).

\section{Physics}

Dosimetry was performed using the Eclipse Treatment Planning System (Varian Medical Systems, Palo Alto, CA) for 3D-CRT and IMRT, and Tomotherapy (Accuray Incorporated, Sunnyvale, CA) software for HT. These systems were employed in the treatment planning performed for every patient. Data reported on HT were calculated by determining the average of the doses prescribed for each of the two patients treated.

\section{Clinical assessment}

For every patient, acute adverse events were recorded weekly, using the Common Terminology Criteria for Adverse Events v 4.0.

\section{Results}

\section{Target volume coverage}

The average doses prescribed to the $100 \%$ of the planning target volumes were $25.1 \mathrm{~Gy}$ to the encephalon (139.4\% of the prescription dose), 40.2 Gy to the posterior cerebral fossa (100.5\%), 18.9 Gy to the spinal cord (105.0\%) with 3D-CRT. The patient treated by IMRT received an average dose of 15.5 Gy to the encephalon (103.3\% of the prescription dose), and 15.7 Gy to the spinal cord (104.6\%). In the case of the two patients treated through HT, both encephalon and spinal cord were targeted with an average dose of 23.3 Gy $(99.5 \%$ of the prescription dose) (Figure 1 and 2). These results are reported in Table 3.

\section{Average doses to organs at risk}

Average doses received according to the plans by the esophagus were 16.0 Gy (3D-CRT), 13.4 Gy (IMRT), and 10.5 Gy (HT), by both lungs 3.3 Gy (3D-CRT), 2.2 Gy (IMRT), and $4.1 \mathrm{~Gy}$ (HT), and by the heart 11.4 Gy (3D-CRT), 8.0 Gy (IMRT), and 4.9 Gy (HT).

According to the treatment plans, the right lens received an average of 5.5 Gy by 3D-CRT, 1.2 Gy by IMRT, and $2.3 \mathrm{~Gy}$ by HT. The left lens had 6.5 Gy with 3D-CRT, 1.0 Gy with IMRT, and 2.3 Gy with HT. The larynx had 6.3 Gy on 3D-CRT, 1.0 Gy with IMRT, and 10.2 Gy on HT. The thyroid gland received 14.2 Gy on 3D-CRT, 12.1 Gy on IMRT, and 6.7 Gy on HT.

\section{All these results are shown in Table 4.}

\section{Acute adverse events}

The patient treated by $3 \mathrm{D}-\mathrm{CRT}$ presented during CSI with grade 
Citation: Jacob J, Vernant JP, Chira C, Mazal A, Zefkili S, et al. (2012) Craniospinal Irradiation (CSI) in Acute Lymphoblastic Leukemia: Comparison between Conformal Radiotherapy, Intensity-Modulated Radiotherapy, and Helical Tomotherapy (HT). J Nucl Med Radiat Ther S6:003. doi:10.4172/2155-9619.S6-003

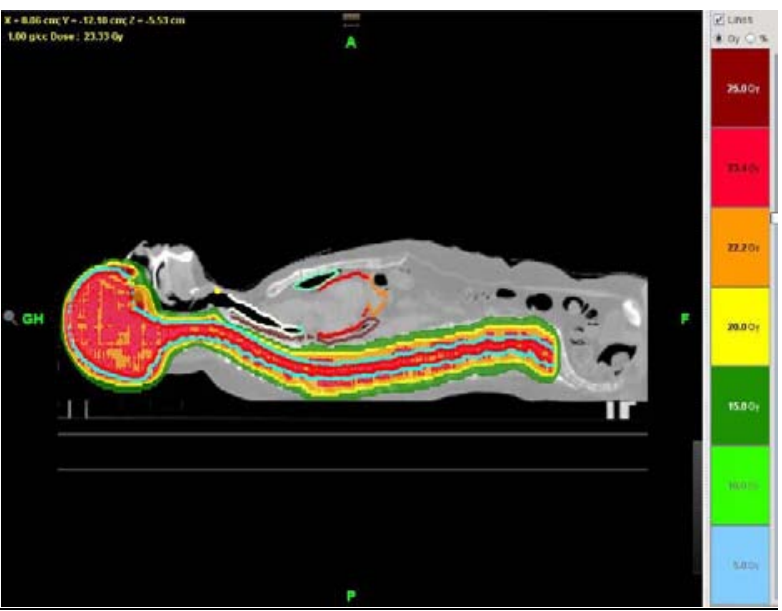

Figure 1: Treatment planning of helical tomotherapy: homogenous coverage of the central nervous system

\begin{tabular}{|c|c|c|c|}
\hline & 3D-CRT & IMRT & HT \\
\hline $\begin{array}{l}\text { Average } \\
\text { doses }\end{array}$ & $\begin{array}{l}\text { E : } 25.185(139.9 \%) \\
\text { PCF : } 40.275(100.6 \%) \\
\text { SC : } 18.941(105.2 \%)\end{array}$ & $\begin{array}{l}E: 15.519(103.4 \%) \\
S C: 15.789(105.2 \%)\end{array}$ & $\begin{array}{l}\text { E : } 23.395(99.9 \%) \\
\text { SC : } 23.395(99.9 \%)\end{array}$ \\
\hline
\end{tabular}

3D-CRT: three dimensional conformal radiotherapy, IMRT: intensity-modulated radiation therapy, HT: helical tomotherapy, E: encephalon, SC: spinal cord, PCF: posterior cerebral fossa.

Table 3: Planned average doses (absolute and relative values, in Gy) by craniospinal irradiation to $100 \%$ of the planning target volumes.

\begin{tabular}{|c|c|c|c|}
\hline Organs & 3D-CRT & IMRT & HT \\
\hline right lens & 5.5 & 1.2 & 2.3 \\
\hline left lens & 6.5 & 1.0 & 2.3 \\
\hline esophagus & 16.0 & 13.4 & 10.5 \\
\hline lungs & 3.3 & 2.2 & 4.1 \\
\hline thyroid & 14.2 & 12.1 & 6.7 \\
\hline larynx & 6.3 & 1.0 & 10.2 \\
\hline
\end{tabular}

3D-CRT: three dimensional conformal radiotherapy, IMRT: intensity-modulated radiation therapy, $\mathrm{HT}$ : helical tomotherapy.

Table 4: Planned average doses (in Gy) by craniospinal irradiation to healthy organs.

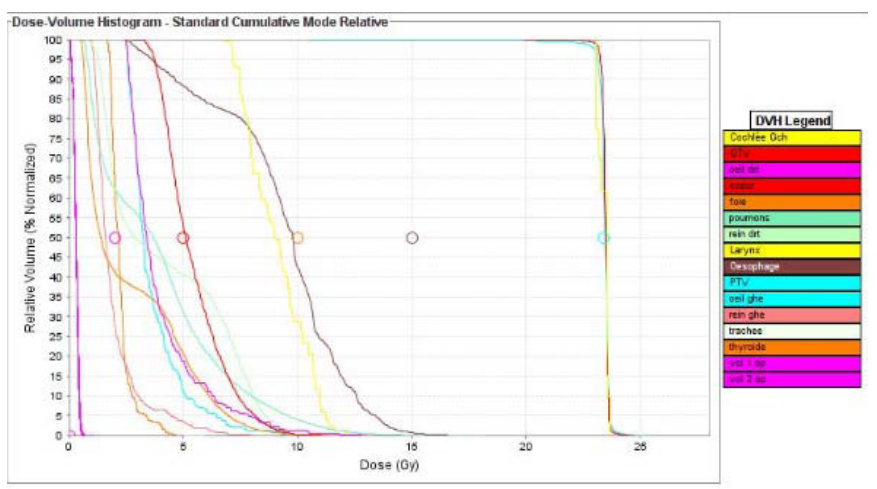

Figure 2: Dose-volume histogram of the treatment plan of helical tomotherapy (Planning Target Volume curve in blue).

II vomiting and asthenia, and grade I epithelitis. She also complained about postural headaches and cervical paresthesias. Biological examination showed grade II pancytopenia, requiring hematopoietic growth factors and platelet transfusions.
Six months after the end of the irradiation, the clinical symptoms completely disappeared, allowing a progressive decrease in the corticotherapy doses. However, the patient developed a loss of sensitivity in the posterior right thigh six months post treatment. The neurological symptoms disappeared three months later. Radiological follow-up by MRI showed a complete regression of the cerebellar lesion and no relapse in the brain or in the medullar axis either. The blood cell count remained normal. Performance status improved so that the patient was able to engage in professional activity.

The young patient whose treatment was performed by IMRT experienced grade II vomiting controlled by symptomatic medication. His performance status was preserved and he developed no other symptoms. No biological abnormality was detectable on the blood cell count. Then, in April 2010, the patient received a pheno-identical allograft following conditioning by TBI (12 Gy in six fractions) and cyclophosphamide.

The first patient treated by HT did not suffer any acute clinical toxicity. He remained asymptomatic during the whole treatment. The biological examination showed a grade 0 anemia (hemoglobin: $10.8 \mathrm{~g} /$ $\mathrm{dL}$ ) and a grade 0 lymphopenia (lymphocytes: $1100 / \mathrm{mm}^{3}$ ), whereas platelets count remained normal.

HT had to be stopped during the second patient's treatment after a dose of 9 Gy was delivered to the CSA. She was admitted to the Hematology department for disease progression.
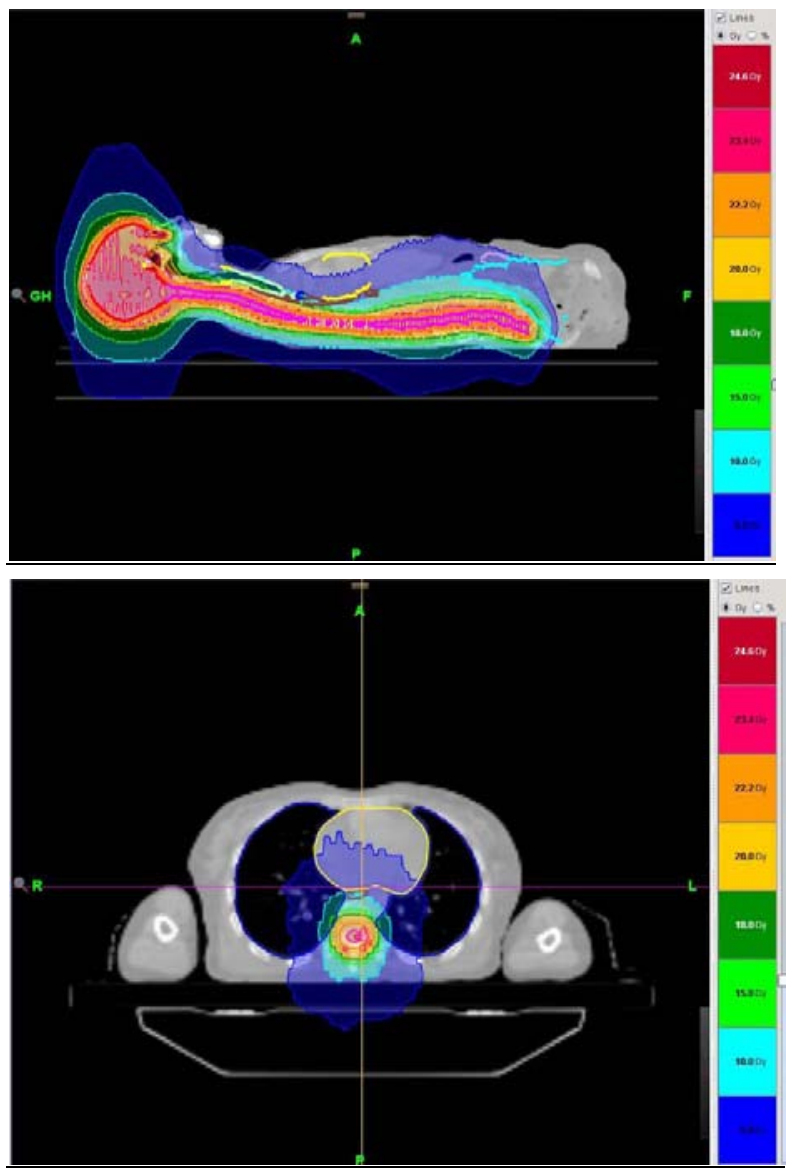

Figure 3: Treatment plan of helical tomotherapy: low doses to healthy organs 
Citation: Jacob J, Vernant JP, Chira C, Mazal A, Zefkili S, et al. (2012) Craniospinal Irradiation (CSI) in Acute Lymphoblastic Leukemia: Comparison between Conformal Radiotherapy, Intensity-Modulated Radiotherapy, and Helical Tomotherapy (HT). J Nucl Med Radiat Ther S6:003. doi:10.4172/2155-9619.S6-003

Page 5 of 6

\section{Discussion}

CSI is usually performed on tumors involving the CNS such as medulloblastomas [16-17], germinomas [18], and ependymomas [19]. As far as hematologic tumors are concerned, lymphomas can constitute an indication for this type of radiation therapy [20]. Intensification therapy, including CSI, has been assessed by Lazarus et al. in patients with acute CNS lymphoblastic leukemia [21]. Despite the treatment, this condition presented a higher risk of CNS relapse and a shorter overall survival. A single cranial irradiation was performed to prevent or treat local failure of this malignant hemopathy [22].

Different techniques have been described to perform radiation therapy on the cranio-spinal axis. Prone position allows efficient coverage of the spinal cord, but risk organs (thyroid gland, mandible, pharynx, and larynx) may receive higher doses [23]. Supine position has been assessed in children [24], delivering doses to the spinal cord similar to the prescription dose, while saving setup time.

CSI may lead to various adverse effects: acute hematologic [25], otologic [26], digestive [27], late endocrine, central and peripheral neurological $[28,29]$ toxicities [30], affected fertility [31,32] and increased risk of second malignancy [33-35].

Due to these potential impairments, different techniques have been studied in order to maintain local control and improve quality of life, such as proton therapy [36], IMRT [37], and hyperfractionation [38]. $\mathrm{HT}$, when indicated for a case of CSI, presents dosimetric advantages, such as no field junction and no discontinuous gantry movements [39]. Despite the relatively long time dedicated to setup and treatment, image guidance with CT assures a precise and safe irradiation [40].

From a physical point-of-view, HT is superior to conformal radiotherapy and IMRT in terms of dose homogeneity index and conformity index. Doses to risk organs are also reduced [41-44].

Compared to conventional radiotherapy, in pediatric patients, this method delivers a lower dose level to the growing vertebrae [45]. Acute pulmonary toxicity is improved [46].

However, the main difficulty encountered with HT is the fact that a substantial volume of healthy tissues receive low doses (Figure 3) $[47,48]$. After calculation of organ-equivalent doses, risk of secondary cancers in relationship to the irradiation of organs at risk seems to be higher with HT than with proton therapy [49]. Variations in spinal cord setup can generate gaps in terms of delivered doses to the CNS between initial dosimetric evaluation and effective treatment [50]. Moreover, in some cases, optic nerve could be partially underdosed, so that the risk of local recurrences would be increased in tumors with tropism for the CNS [51].

\section{Conclusion}

According to our study, compared to conformal radiotherapy, HT covers efficiently the planning target volume and contributes to local control while delivering lower doses to risk organs. Despite a longer time dedicated to set-up and treatment, acute adverse events are acceptable. Hence, HT constitutes a reliable modality of CSI. Main drawbacks of this technique are low-dose distribution to healthy tissues and variations in setup despite daily monitoring by CT. A longer follow-up of these patients, especially young ones, is warranted to assess chronic toxicity related to the treatment, particularly secondary malignancies.

\section{Acknowledgements}

To Acuray France for the help in this paper's revision

\section{References}

1. Faderl S, O'Brien S, Pui CH, Stock W, Wetzler M, et al. (2010) Adult acute lymphoblastic leukemia: concepts and strategies. Cancer 116: 1165-1176.

2. Faderl S, Jeha S, Kantarjian HM (2003) The biology and therapy of adult acute lymphoblastic leukemia. Cancer 98: 1337-1354.

3. Clavel J, Goubin A, Auclerc MF, Auvrignon A, Waterkeyn C, et al. (2004) Incidence of childhood leukaemia and non-Hodgkin's lymphoma in France: National Registry of Childhood Leukaemia and Lymphoma, 1990-99. Eur J Cancer Prev 13: 97-103.

4. Troussard X, Duchenet V, Cornet E, Mouchel D, Malet M, et al. (2009) Haematological malignancies : incidence in Basse-Normandie, France, for 1997-2004. Rev Epidemiol Sante Publique 57: 151-158.

5. Thomas X, Le QH (2003) Prognostic factors in adult acute lymphoblastic leukemia. Hematology 8: 233-242.

6. Verma A, Stock W (2001) Management of adult acute lymphoblastic leukemia: moving toward a risk-adapted approach. Curr Opin Oncol 13: 14-20.

7. Thomas X, Le QH (2008) Central nervous system involvement in adult acute lymphoblastic leukemia. Hematology 13: 293-302.

8. Jabbour EJ, Faderl S, Kantarjian HM (2005) Adult acute lymphoblastic leukemia. Mayo Clin Pro 80: 1517-1527.

9. Sancho JM, Ribera JM, Oriol A, Hernandez-Rivas JM, Rivas C, et al. (2006) Central nervous system recurrence in adult patients with acute lymphoblastic leukemia: frequency and prognosis in 467 patients without cranial irradiation for prophylaxis. Cancer 106: 2540-2546.

10. Jabbour E, Thomas D, Cortes J, Kantarjian HM, O'Brien S (2010) Centra nervous system prophylaxis in adults with acute lymphoblastic leukemia: current and emerging therapies. Cancer 116: 2290-300.

11. Surapaneni UR, Cortes JE, Thomas D, O'Brien S, Giles FJ, et al. (2002) Central nervous system relapse in adults with acute lymphoblastic leukemia. Cancer 94: 773-779.

12. Pui $\mathrm{CH}$, Thiel E (2009) Central nervous system disease in hematologic malignancies: historical perspectives and practical applications. Semin Onco 36: S2-S16.

13. Welsh JS, Mehta MP, Mackie TR, Orton N, Jaradat H, et al. (2005) Helica tomotherapy as a means of delivering scalp-sparing whole brain radiation therapy. Technol Cancer Res Treat 4: 661-662; author reply 662.

14. Cozzarini C, Fiorino C, Di Muzio N, Alongi F, Broggi S, et al. (2007) Significan reduction of acute toxicity following pelvic irradiation with helical tomotherapy in patients with localized prostate cancer. Radiother Oncol 84: 164-170.

15. Moon SH, Jung YS, Ryu JS, Choi SW, Park JY, et al. (2010) Outcomes of postoperative simultaneous modulated accelerated radiotherapy for head-andneck squamous cell carcinoma. Int J Radiat Oncol Biol Phys 81: 140-149.

16. Van Dyk J, Jenkin RD, Leung PM, Cunningham JR (1977) Medulloblastoma: Treatment technique and radiation dosimetry. Int J Radiat Oncol Biol Phys 2 993-1005.

17. Dewit L, Van Dam J, Rijnders A, van de Velde G, Ang KK, et al. (1984) A modified radiotherapy technique in the treatment of medulloblastoma. Int Radiat Oncol Biol Phys 10: 231-241.

18. Merchant TE, Sherwood SH, Mulhern RK, Rose SR, Thompson SJ, et al. (2000) CNS germinoma: disease control and long-term functional outcome for 12 children treated with craniospinal irradiation. Int J Radiat Oncol Biol Phys 46: 1171-1176.

19. Schuller P, Schafer U, Micke O, Willich N (1999) Radiotherapy for intracrania and spinal ependymomas. A retrospective analysis. Strahlenther Onkol 175 105-111.

20. Lee DK, Chung CK, Kim HJ, Kim K, Choe G, et al. (2002) Multifocal primary CNS T cell lymphoma of the spinal cord. Clin Neuropathol 21: 149-155.

21. Lazarus HM, Richards SM, Chopra R, Litzow MR, Burnett AK, et al. (2006) Central nervous system involvement in adult acute lymphoblastic leukemia at diagnosis: results from the international ALL trial MRC UKALL-XII/ECOG E2993. Blood 108: 465-472.

22. Pui CH (2006) Central nervous system disease in acute lymphoblastic leukemia: prophylaxis and treatment. Hematology Am Soc Educ Program 1: 142-146. 
Citation: Jacob J, Vernant JP, Chira C, Mazal A, Zefkili S, et al. (2012) Craniospinal Irradiation (CSI) in Acute Lymphoblastic Leukemia: Comparison between Conformal Radiotherapy, Intensity-Modulated Radiotherapy, and Helical Tomotherapy (HT). J Nucl Med Radiat Ther S6:003. doi:10.4172/2155-9619.S6-003

Page 6 of 6

23. Narayana A, Jeswani S, Paulino AC (1999) The cranial-spinal junction in medulloblastoma : does it matter? Int J Radiat Oncol Biol Phys 44: 81-84.

24. Prabhakar R, Haresh KP, Munshi A, Sridhar PS, Subramani V, et al. (2009) A simple technique for cranio-spinal irradiation in pediatric patients. J Can Res Ther 5: 113-115.

25. Jefferies S, Rajan B, Ashley S, Traish D, Brada M (1998) Haematological toxicity of cranio-spinal irradiation. Radiother Oncol 48: 23-27.

26. Fukunaga-Johnson N, Sandler HM, Marsh R, Martel MK (1998) The use of 3D conformal radiotherapy (3D CRT) to spare the cochlea in patients with medulloblastoma. Int J Radiat Oncol Biol Phys 41: 77-82.

27. Huang F, Parker W, Freeman CR (2010) Feasibility and early outcomes of supine-position of cranio-spinal irradiation. Pediatr Blood Cancer 54: 322-325.

28. Syndikus I, Tait D, Ashley S, Jannoun L (1994) Long-term follow-up of young children with brain tumors after irradiation. Int $\mathrm{J}$ Radiat Oncol Biol Phys 30: 781-787.

29. Abd-el-Aal HH, Mokhtar MM, Habib EE, El-Kashef AT, Fahmy ES (2005) Medulloblastoma: conventional radiation therapy in comparison to chemo radiation therapy in the post-operative treatment of high-risk patients. J Egypt Natl Canc Inst 17: 301-307.

30. Littman P, Rosenstock JG, Bailey C (1978) Radiation myelitis following craniospinal irradiation with concurrent actinomycin-D therapy. Med Pediat Oncol 5: 145-151.

31. Wo JY, Viswanathan AN (2009) Impact of radiotherapy on fertility, pregnancy, and neonatal outcomes in female cancer patients. Int J Radiat Oncol Biol Phys 73: $1304-1312$

32. Harden SV, Twyman N, Lomas DJ, Williams D, Burnet NG, et al. (2003) A method for reducing ovarian doses in whole neuro-axis irradiation for medulloblastoma. Radiother Oncol 69: 183-188.

33. Bathia S, Sather HN, Pabustan OB, Trigg ME, Gaynon PS, et al. (2002) Low incidence of second neoplasms among children diagnosed with acute lymphoblastic leukemia after 1983. Blood 99: 4257-4264.

34. Pui CH, Cheng C, Leung W, Rai SN, Rivera GK, et al. (2003) Extended followup of long term survivors of childhood acute lymphoblastic leukemia. $N$ Engl J Med 349: 640-649.

35. Duffner PK, Krischer JP, Horowitz ME, Cohen ME, Burger PC, et al. (1998) Second malignancies in young children with primary brain tumors following treatment with prolonged postoperative chemotherapy and delayed irradiation: a Pediatric Oncology Group study. Ann Neurol 44: 313-316.

36. Fossati P, Ricardi U, Orecchia R (2009) Pediatric medulloblastoma : toxicity of current treatment and potential role of protontherapy. Cancer Treat Rev 35: 79-96

37. Pai Panandiker A, Ning H, Likhacheva A, Ullman K, Arora B, et al. (2007) Craniospinal irradiation with spinal IMRT to improve target homogeneity. Int J Radiat Oncol Biol Phys 68: 1402-1409.

38. Corrias A, Einaudi S, Ricardi U, Sandri A, Besenzon L, et al. (2001) Thyroid diseases in patients during pre-puberty for medulloblastoma with different radiotherapic protocols. J Endocrinol Invest 24: 387-392

39. Bauman G, Yartsev S, Coad T, Fisher B, Kron T (2005) Helical tomotherapy fo craniospinal radiation. $\mathrm{Br} \mathrm{J}$ Radiol 78: 548-552.

40. Sterzing F, Schubert K, Sroka-Perez G, Kalz J, Debus J, et al. (2008) Helical tomotherapy. Experience of the first 150 patients in Heidelberg. Strahlenther Onkol 184: 8-14

41. Sharma DS, Gupta T, Jalali R, Master Z, Phurailatpam RD, et al. (2009) High-precision radiotherapy for craniospinal irradiation: evaluation of threedimensional conformal radiotherapy, intensity-modulated radiation therapy and helical TomoTherapy. Br J Radiol 82: 1000-1009.

42. Mavroidis P, Ferreira BC, Shi C, Delichas MG, Lind BK, et al. (2009) Comparison of the helical tomotherapy and MLC-based IMRT radiation modalities in treating brain and cranio-spinal tumors. Technol Cancer Res Treat 8: 3-14.

43. Shi C, Penagaricano J, Papanikolaou N (2008) Comparison of IMRT treatment plans between linac and helical tomotherapy based on integral dose and inhomogeneity index. Med Dosim 33: 215-221.

44. Penagaricano JA, Papanikolaou N, Yan Y, Youssef E, Ratanatharathorn V (2005) Feasibility of cranio-spinal axis radiation with the Hi-Art tomotherapy system. Radiother Oncol 76: 72-78.

45. Kunos CA, Dobbins DC, Kulasekere R, Latimer B, Kinsella TJ (2008) Comparison of helical tomotherapy versus conventional radiation to delive craniospinal radiation. Technol Cancer Res Treat 7: 227-233.

46. Penagaricano J, Moros E, Corry P, Saylors R, Ratanatharathorn V (2009) Pediatric craniospinal axis irradiation with helical tomotherapy: patient outcome and lack of acute pulmonary toxicity. Int J Radiat Oncol Biol Phys 75: 11551161.

47. Parker W, Brodeur M, Roberge D, Freeman C (2010) Standard and nonstandard craniospinal radiotherapy using helical TomoTherapy. Int J Radiat Oncol Bio Phys 77: 926-931.

48. Penagaricano JA, Shi C, Ratanatharathorn V (2005) Evaluation of integral dose in cranio-spinal axis irradiation (CSA) with conventional and helical delivery. Technol Cancer Res Treat 4: 683-689.

49. Yoon M, Shin DH, Kim J, Kim JW, Kim DW, et al. (2010) Craniospinal Irradiation Techniques: A Dosimetric Comparison of Proton Beams with Standard and Advanced Photon Radiotherapy. Int J Radiat Oncol Biol Phys 81: 637-646.

50. Stoiber EM, Giske K, Schubert K, Sterzing F, Habl G, et al. (2010) Local setup reproductibility of the spinal column when using intensity-modulated radiation therapy for craniospinal irradiation with patient in supine position. Int $\mathrm{J}$ Radiat Oncol Biol Phys 18: 1552-1559.

51. Rene NJ, Brodeur M, Parker W, Roberge D, Freeman C (2010) A comparison of optic nerve dosimetry in craniospinal radiotherapy planned and treated with conventional and intensity modulated techniques. Radiother Oncol 97: 387389 .
This article was originally published in a special issue, Cancer Radiation Therapy handled by Editor(s). Dr. XinChen, University of Arkansas for Medical Sciences, USA 